\title{
MENGEMBANGKAN KEMAMPUAN KONEKSI MATEMATIS SISWA MELALUI PENDEKATAN DIFFERENTIATED INSTRUCTION
}

\section{Eni Defitriani ${ }^{凶}$}

Prodi Pendidikan Matematika, Universitas Batanghari Jambi

\begin{abstract}
Info Artikel
Abstract

Sejarah Artikel:

Diterima 25Agt 2018

Direvisi 4 Sept 2018

Disetujui 29 Okt 2018

Keywords: mathematical connection, Differentiated Instruction (DI) approach

Paper type:

Research paper

The objective of this research was to find out differences the enhance of mathematical connection ability of students who obtained learning with Differentiated Instruction (DI) approach and students who obtained conventional learning $(K V)$. This research was a quasi experiment with non equivalent control group design. The population was all students grade VIII in one of Junior High School at Bandung. The samples consisted of two classes, that are the experimental class with 29 students who obtained learning with Differentiated Instruction (DI) approach and control class with 31 students who obtained conventional learning $(K V)$. The Samples selected with purposive sampling. The data were analyzed by nonparametric statistical Mann-Whitney. Based on the analysis result, it was found that the $N$-gain average score of mathematical connection's DI was 0,43 (medium) while the N-gain average score of mathematical connection's $K V$ was 0,25 (low). This means that the enhance of mathematical connection ability of students who obtained learning with DI approach was better than students who obtained conventional learning. DI approach by grouping using interests more effectively facilitates students to making connection in the discussion.
\end{abstract}

\begin{abstract}
Abstrak
Penelitian ini bertujuan untuk mengetahui perbedaan peningkatan kemampuan koneksi matematis siswa yang belajar dengan pendekatan Differentiated Instruction (DI) dan siswa yang belajar dengan pendekatan konvensional (KV). Jenis penelitian ini adalah quasi eksperimen dengan desain kelompok kontrol non ekuivalen. Populasi berasal dari seluruh siswa kelas VIII salah satu SMP Negeri Bandung. Sampel terdiri dari dua kelas, yaitu kelas eksperimen yang berjumlah 29 siswa yang diberi pembelajaran dengan pendekatan DI dan kelas kontrol yang berjumlah 31 siswa yang diberi pembelajaran dengan pendekatan konvensional. Pemilihan sampel dilakukan dengan teknik purposive sampling. Analisis data dengan statistik nonparametrik Mann-Whitney $U$. Hasil analisis data menunjukkan bahwa skor rata-rata $N$-gain kemampuan koneksi matematis siswa DI sebesar 0,43 (kategori sedang) sedangkan skor rata-rata $N$-gain kemampuan koneksi matematis siswa KV sebesar 0,25(kategori rendah). Hal ini berarti bahwa peningkatan kemampuan koneksi matematis siswa yang belajar dengan pendekatan DI lebih baik daripada siswa yang belajar dengan pendekatan konvensional. Pembelajaran DI dengan pengelompokkan berdasarkan minat lebih efektif memfasilitasi siswa melakukan aktivitas koneksi dalam proses diskusi.
\end{abstract}

(C) 2018 Universitas Muria Kudus

\footnotetext{
Alamat korespondensi:

Program Studi Pendidikan Matematika, Universitas Muria Kudus

Kampus UMK Gondangmanis, Bae Kudus Gd. L. lantai 1 Ruang 2 PO. BOX 53 Kudus

Tlp (0291) 438229 Fax. (0291) 437198

E-mail: e.defitrianiz@gmail.com
} 
Eni Defitriani

Anargya: Jurnal Pendidikan Matematika, Vol. 1 No. 2, Oktober 2018

\section{PENDAHULUAN}

Matematika adalah cabang ilmu pengetahuan yang berperan penting dalam kehidupan manusia yang dikenal dengan istilah mathematics is a human activity. Matematika juga tidak dapat berdiri sendiri. Agar lebih bermakna, matematika harus dipadankan (connecting) dengan bidang ilmu lain untuk memecahkan masalah dalam kehidupan seharihari. Salah satu tujuan mata pelajaran matematika pada setiap jenjang pendidikan adalah agar siswa memahami konsep matematika, menjelaskan keterkaitan antar konsep, dan mengaplikasikan konsep atau logaritma secara luwes, akurat, efesien dan tepat dalam pemecahan masalah (Depdiknas ,2006) dan disebut dengan koneksi matematis (NCTM , 2000).

Koneksi matematis membantu siswa dalam proses pembelajaran yang bermakna (Wahyudin, 2008), yang tergambar ketika siswa dapat menghubungkan sekaligus menerapkan satu konsep matematika kedalam konsep matematika atau disiplin ilmu lainnya atau dalam kehidupan sehari-hari (Sumarmo, 2013), sehingga pemahaman siswa lebih mendalam dan tahan lama (NCTM, 2000). Ketika siswa memiliki kemampuan koneksi, siswa tidak akan merasa bosan dan sukar dalam belajar matematika karena siswa tidak perlu mengingat konsep dan prosedur matematika yang banyak (NCTM, 2000). Hal inilah yang menjadi momok bagi siswa dalam belajar matematika. Melalui koneksi, siswa akan sadar bahwa matematika itu bukan kumpulan ide atau topik yang saling terlepas namun merupakan satu set ide yang saling berelasi (Sumarmo, 2013).

Fakta dilapangan menunjukkan bahwa kemampuan koneksi matematis siswa masih belum baik. Hasil ini diperlihatkan oleh Fauzi (2012) dan Nurfitria (2013). Fauzi (2012) mengemukakan bahwa kemampuan koneksi matematis siswa walaupun di level sekolah tinggi masih rendah. Sedangkan Nurfitria (2013) menemukan bahwa sekitar $65,7 \%$ siswa tidak dapat menjawab soal sesuai dengan indikator koneksi. Rendahnya kemampuan koneksi siswa ini disebabkan oleh beberapa faktor, salah satunya adalah pembelajaran matematika di kelas yang belum maksimal. Siswa cenderung pasif dan tidak belajar mengkontruksi pengetahuannya sendiri, karena proses pembelajaran yang bersifat teacher centered. Selain itu, proses pembelajaran bersifat melayani siswa keseluruhan tanpa memperhatikan perbedaan minat, motivasi, dan kebutuhan siswa (Sumarmo 2013). Sementara itu, proses pembelajaran yang memfasilitasi pengembangan kemampuan koneksi matematis sebaiknya dilakukan sendiri oleh siswa dengan cara berdiskusi (Sugiman, 2008), karena koneksi adalah aktivitas yang terjadi secara alami dalam diri siswa (Businskas, 2008).

Selain itu, faktor perbedaan karakteristik dalam diri siswa juga tidak boleh diabaikan. Siswa akan sukses, jika unsur-unsur keberagaman siswa diperhatikan (Peterson, 2007). Oleh sebab itu, diperlukan suatu pembaharuan dalam proses pembelajaran yang dapat mengakomodir perbedaan-perbedaan siswa, yaitu salah satunya adalah pendekatan Differentiated Instruction (DI).

DI adalah suatu pembelajaran yang memaksimalkan potensi setiap siswa dengan memperhatikan kebutuhan siswa (Tomlinson, 2000). DI dapat diibaratkan seperti resep dokter, yang diberikan sesuai dengan dosis yang dibutuhkan pasien sehingga dapat sembuh dari penyakit (Defitriani, 2015). Pada pembelajaran dengan pendekatan DI, siswa diberikan kesempatan yang lebih banyak untuk mengeksplorasi matematika dengan semua potensi yang dimilikinya. DI dirancang untuk membelajarkan semua siswa dengan cara yang mereka inginkan. Seperti yang dikemukan oleh Bao (2010) "If children do not learn the way we teach them, then we must teach them the way they learn". Ketika siswa difasilitasi belajar sesuai dengan keinginan dan kebutuhannya, maka siswa akan belajar dan potensinya akan berkembang dengan optimal. Hal ini seperti yang diungkapkan oleh Fauzi (2012) bahwa ketika siswa belajar, maka ia akan paham, selanjutnya ia akan mampu membuat koneksi.

Pembelajaran DI yang efektif adalah kerja kelompok (Butler dan Lowe, 2008). Pengelompokkan akan memudahkan siswa untuk berinteraksi dengan teman-temannya dalam memahami dan menyelesaikan masalah matematika. Pengelompokkan yang diterapkan adalah pengelompokkan fleksibel. Regrouping harus menjadi proses yang dinamis, berubah sesuai dengan konten, proyek, dan terus menerus dievaluasi (Bao, 2010). Oleh sebab itu, perbedaan individual siswa dapat disinergikan menjadi kekuatan yang dapat membuat siswa menjadi lebih efektif dalam belajar matematika (Defitriani, 2015)

Dengan demikian, pembelajaran dengan penekatan DI diduga dapat meningkatkan kemampuan koneksi matematis siswa. Oleh sebab itu, dalam penelitian ini akan mengungkapkan apakah terdapat perbedaan peningkatan kemampuan koneksi matematis 
siswa yang memperoleh pembelajaran DI dan siswa yang memperoleh pembelajaran konvensional (KV).

\section{METODE PENELITIAN}

Metode penelitian ini adalah kuasi eksperimen. Hal ini dikarenakan penelitian yang dilakukan menerima keadaan subjek sebagaimana adanya dan subjek tidak dapat dikelompokkan secara acak karena akan mengganggu administratif sekolah. Penelitian ini menggunakan dua kelompok sampel, yaitu kelas eksperimen yang diberikan perlakuan berupa pembelajaran dengan pendekatan Differentiated Instruction (DI), dan kelas kontrol yang tidak diberikan perlakuan (pembelajaran konvensional). Desain penelitian ini adalah desain kelompok kontrol non-ekuivalen, yang diilustrasikan sebagai berikut:

Kelas Eksperimen:

Kelas Kontrol<smiles>CO[14Co]=O</smiles>

Keterangan:

$\mathrm{X}=$ pembelajaran dengan pendekatan Differentiated Instruction

$\mathrm{O}=$ tes (pretes dan postes kemampuan koneksi matematis)

--- = pengambilan sampel tidak dilakukan secara acak

Populasi dalam penelitian ini adalah seluruh siswa kelas VIII pada salah satu SMP Negeri di Kota Bandung tahun ajaran 2014/2015. Sampel penelitian terdiri dari 29 siswa kelas eksperimen dan 31 siswa kelas kontrol, yang dipilih dengan teknik purposive sampling, yaitu teknik penentuan sampel dengan pertimbangan tertentu. Sampel dipilih dengan pertimbangan kedua kelas dibimbing oleh guru yang sama dan memiliki karakteristik serta kemampuan akademik yang relatif setara.

Data yang dikumpulkan adalah kemampuan koneksi matematis siswa, sehingga instrumen yang digunakan adalah tes kemampuan koneksi matematis yang disusun berdasarkan indikator kemampuan koneksi matematis, yaitu: (1) mencari hubungan berbagai representasi konsep dan prosedur; (2) memahami dan menggunakan antar konsep dan prosedur dalam topik matematika; (3) mencari hubungan satu prosedur ke prosedur lain dalam representasi yang ekuivalen; dan (4) menggunakan matematika dalam kehidupan sehari-hari.

Tes diberikan sebelum dan setelah diberikan perlakuan. Hal ini dikarenakan, tujuan dalam penelitian ini adalah untuk mengungkap perbedaan peningkatan kemampuan koneksi antara siswa yang memperoleh pembelajaran DI dan KV. Sehingga, data yang diolah adalah data n-gain.

Analisis data dilakukan dengan bantuan program SPSS 17.0 for windows dengan uji statistisk nonparametrik Mann Whitney, karena data tidak berdistribusi normal.

\section{HASIL DAN PEMBAHASAN}

Pembelajaran dengan pendekatan Differentiated Instruction (DI) yang digunakan dalam penelitian ini menerapkan strategi pembelajaran yang berbeda dan pengelompokkan fleksibel pada setiap pertemuannya, disesuaikan dengan materi yang dipelajari. Strategi-strategi yang digunakan pada pertemuan pertama sampai keenam secara berturut-turut adalah strategi pembelajaran kooperatif dengan aktivitas quick on the draw (materi luas permukaan kubus dan balok dan pengelompokkan heterogen), tugas berjenjang (materi luas permukaan prisma dengan pengelompokkan berdasarkan kesiapan belajar), tic tac toe (materi luas permukaan limas dengan pengelompokkan berdasarkan minat siswa), DI berdasarkan gaya belajar (materi volume kubus dan balok dengan pengelompokkan berdasarkan gaya belajar: audio, kinestetik, dan visual), presentasi (materi volume limas dan prisma), dan menu offers (review materi).

Berdasarkan hasil pengolahan data, statistik deskriptif skor pretes, postes, dan $N$ Gain kemampuan koneksi matematis siswa pada kedua kelas dapat dilihat pada tabel 1 di bawah ini.

Tabel 1. Statistik Deskriptif Kemampuan Koneksi Matematis Siswa

\begin{tabular}{|c|c|c|c|c|c|c|}
\hline \multirow{2}{*}{ Data } & \multicolumn{3}{|c|}{$\begin{array}{c}\text { Differentiated } \\
\text { Instruction (DI) }\end{array}$} & \multicolumn{3}{|c|}{ Konvensional (KV) } \\
\hline & Pre & Pos & $\begin{array}{c}N- \\
\text { gain }\end{array}$ & Pre & Pos & $N$-gain \\
\hline $\mathbf{N}$ & 29 & 29 & 29 & 31 & 31 & 31 \\
\hline Min. & 0 & 2 & 0,05 & 0 & 0 & 0 \\
\hline Max. & 12 & 40 & 0,90 & 12 & 42 & 0,94 \\
\hline $\bar{x}$ & 1,86 & 19,65 & 0,43 & 2,00 & 11,63 & 0,25 \\
\hline SD & 2,50 & 12,88 & 0,29 & 3,27 & 12,27 & 0,27 \\
\hline \multicolumn{7}{|c|}{ Skor Maksimum Pretes/Postes = 44} \\
\hline
\end{tabular}

Secara deskriptif diketahui bahwa bahwa rata-rata skor pretes kelas $\mathrm{KV}$ lebih tinggi 0,14 dari kelas DI. Rata-rata skor postes kelas DI lebih tinggi daripada kelas KV sebesar 8,02. Sedangkan skor $\mathrm{N}$-gain kelas DI lebih tinggi sebesar 0,18 dari kelas KV. Untuk melihat perbedaan secara signifikan, dilakukan uji statistik. Namun sebelum itu, dilakukan terlebih dahulu uji pasyarat normalitas ddan 
homogenitas. Hasil uji normalitas skor $N$-gain menunjukkan bahwa data berasal dari populasi yang tidak berdistribusi normal, secara visualisasi dapat dilihat pada tabel 2 .

Tabel 2. Uji Normalitas Skor N-gain Kemampuan Koneksi Matematis Siswa

\begin{tabular}{|c|c|c|c|c|c|}
\hline \multirow{2}{*}{ Kelas } & \multicolumn{3}{|c|}{$\begin{array}{c}\text { Kolmogorov- } \\
\text { Smirnov } \\
\end{array}$} & \multirow{2}{*}{ Kesimpulan } & \multirow{2}{*}{ Ket. } \\
\hline & Statistic & $D f$ & Sig. & & \\
\hline DI & 0,175 & 29 & $\begin{array}{c}0,02 \\
3\end{array}$ & $\mathrm{H}_{\mathrm{o}}$ ditolak & $\begin{array}{l}\text { Tidak } \\
\text { Normal }\end{array}$ \\
\hline KV & 0,232 & 31 & $\begin{array}{c}0,00 \\
0\end{array}$ & $\mathrm{H}_{\mathrm{o}}$ ditolak & $\begin{array}{l}\text { Tidak } \\
\text { Normal }\end{array}$ \\
\hline
\end{tabular}

Karena data berasal dari poulasi yang tidak berdistribusi normal, maka analisis data menggunakan statistik nonparamterik Mann Whitney. Berikut hasil uji statistiknya.

Tabel 3. Uji Perbedaan Skor $N$-gain Kemampuan Koneksi Matematis Siswa

\begin{tabular}{ccccc}
\hline \multicolumn{4}{c}{ Statistik } & \\
\cline { 1 - 3 } Mann- & & Asymp. & Asymp. & Ket \\
Whitney & $Z$ & Sig. (2- & Sig. (1- & \\
$\boldsymbol{U}$ & & $\begin{array}{c}\text { tailed) } \\
\text { tailed) }\end{array}$ & \\
$\mathbf{2 8 1 , 5 0 0}$ & $-2,490$ & 0,013 & 0,0065 & $\mathrm{H}_{0}$ ditolak \\
\hline
\end{tabular}

Berdasarkan tabel 3 di atas, dapat disimpulkan bahwa kemampuan koneksi matematis siswa yang memperoleh pembelajaran dengan pendekatan Differentiated Instruction (DI) lebih baik daripada siswa yang memperoleh pembelajaran konvensional (KV). Hasil ini tentunya tidak terlepas dari kontribusi pembelajaran yang diterapkan dalam penelitian ini, yaitu pembelajaran dengan pendekatan Differentiated Instruction (DI).

Pembelajaran DI memfasilitas siswa untuk melakukan koneksi karena menggunakan kerja kelompok, yang mengakibatkan siswa dapat melakukan diskusi dan interasi untuk saling menyampaikan, menanggapi, dan merespon serta melihat koneksi antar konsep dalam matematika. Sehingga siswa akan menghasilkan prestasi (menghubungkan konsep dalam matematika) yang lebih baik ketika belajar bersama daripada belajar secara inividu yang akan menciptakan persaingan dan mereduksi hasil belajar (Kusnandar, 2011).

Peningkatan kemampuan koneksi siswa yang belajar dengan pendekatan DI, juga disebabkan oleh fleksibel grouping yang menjadi ciri khas DI. Pengelompokkan yang fleksibel, artinya siswa tidak selamanya dikelompokkan secara heterogen namun juga bisa dikelompokkan secara homogen. Pengelompokkan secara heterogen berdasarkan tingkat intelegensi, agar siswa yang pandai dapat membantu siswa yang kurang pandai dalam membuat keterkaitan dalam konsep matematika dan dalam kehidupan sehari-hari. Sedangkan pengelompokkan homogen berdasarkan dengan gaya belajar, kesiapan belajar, dan profil belajar yang sama. Hal ini akan membuat siswa merasa nyaman dalam belajar karena bersama orangorang yang "setipe", sehingga potensi untuk melakukan dan melihat keterkaitan atau hubungan dalam belajar matematika berkembang secara optimal.

Selain itu, pemberian tugas non rutin dalam pembelajaran DI juga meningkatkan kemampuan koneksi siswa. Tugas non rutin atau tugas yang bersifat terbuka akan mengembangkan strategi kognitif siswa dalam membuat koneksi (Sumarmo, 2013). Hal ini dapat dilihat dari kontribusi indikator kemampuan koneksi yang diberikan kepada siswa untuk mengukur peningkatan kemampuan koneksinya, yaitu indikator mencari hubungan satu prosedur ke prosedur lain dalam representasi yang ekuivalen. Hasil analisis menunjukkan bahwa skor $\mathrm{N}$-gain soal (gambar 1) dengan indikator ini adalah sebesar 0,5 (kategori sedang).

Peningkatan kemampuan koneksi siswa pada indikator ini tidak terlepas dari pembelajaran DI yang diterapkan untuk melatih indikator ini, yaitu pembelajaran DI dengan strategi pembelajaran tic tac toe dan pengelompokkan berdasarkan minat siswa. Strategi tic tac toe, memberikan kesempatan kepada siswa untuk berpartisipasi dalam beberapa tugas, sehingga melatih keterampilan (mencari hubungan) yang telah dipelajari dan menunjukkan serta memperluas pemahaman konsep mereka. Agar siswa dapat melakukan koneksi, siswa harus memahami informasiinformasi yang diterimanya terlebih dahulu, sehingga dapat mengaitkan ide-ide matematis yang diperoleh. Agar siswa dapat memahami informasi, maka siswa harus belajar terlebih dahulu (Fauzi, 2012). Pada pertemuan ini, siswa belajar dengan pengelompokan berdasarkan minat (individu, berpasangan, kelompok), sehingga siswa merasakan kenyamanan yang mengakibatkan siswa belajar. 


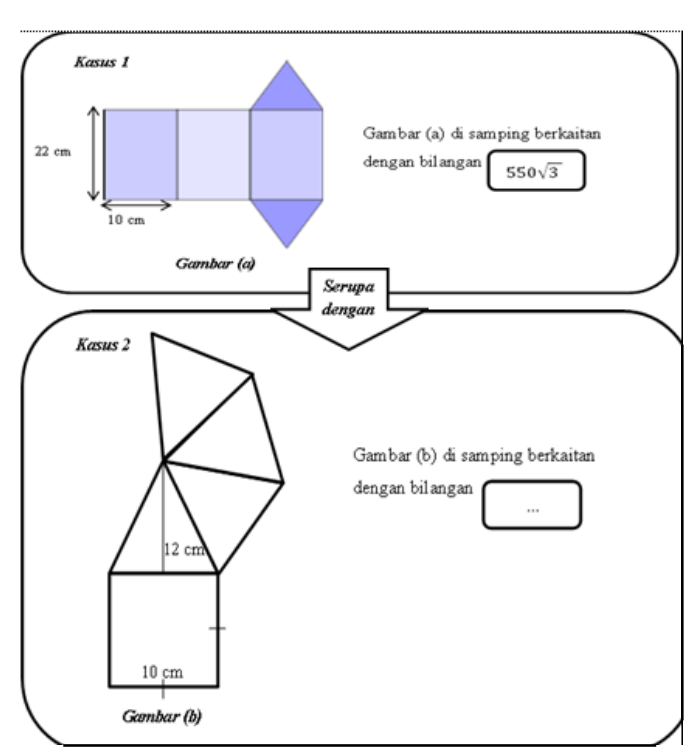

Gambar 1

Selain itu, untuk memfasilitasi kebutuhan siswa dalam pembelajaran dengan pendekatan DI guru menerapkan scaffolding pada Zona Perkembangan Proksimal (ZPD) siswa. Hal ini dilakukan untuk menyesuaikan kebutuhan dan pemahaman siswa yang berbeda sekaligus memberikan dukungan emosional kepada siswa, agar dapat memaksimalkan prestasi siswa dalam menemukan keterkaitan dalam konsep dan posedur matematika.

\section{SIMPULAN}

Implementasi pembelajaran dengan pendekatan DI akan lebih efektif untuk meningkatkan kemampuan koneksi matematis ketika menggunakan pengelompokkan berdasarkan minat siswa (individu, berpasangan, atau diskusi kelompok). Hal ini berdasarkpan learning profile siswa yang berbeda dan kenyamanan siswa dalam proses diskusi, sehingga aktivitas diskusi memfasilitasi siswa untuk melakukan koneksi.

\section{UCAPAN TERIMA KASIH}

Penulis ucapkan terima kasih kepada kepada semua pihak yang tidak dapat disebutkan satu persatu, yang telah membantu dalam pelaksanaan penelitian hingga penulisan artikel ini. Penulis juga mengucapkan terimakasih kepada segenap tim Pengelola Jurnal Anargya yang telah memberikan kesempatan kepada penulis untuk mempublikasikan karya ilmiahnya.

\section{DAFTAR PUSTAKA}

Bao . 2010. Teaching and Learning Strategies for Differentiated Instruction in the Language Classroom. [Online]. Tersedia: http://steinhardt.nyu.edu/teachlearn /dclt/Summer_Institute_2010. [20 Oktober 2014]

Butler, M. and Van Lowe, K. 2008. Using Differentiated Instruction in Teacher Education. International Journal for Mathematics Teaching and Learning.

Businskas. 2008. Conversation About Connection: How Secondary Mathematics Teacher Conceptualize and Contend with Mathematical Connection (Dissertation). Canada: Simobn Fraser University

Defitriani. 2015. Penerapan Pendekatan Differentiated Instruction untuk Meningkatkan Kemampuan Koneksi Matematis dan Disposisi Matematis Siswa SMP (Tesis). Bandung: Universitas Pendidikan Indonesia

Depdiknas. 2006. Panduan Penyusunan Kurikulum Tingkat Satuan Pendidikan. Jakarta: Badan Standar Nasional Pendidikan

Fauzi. 2012. Peningkatan Kemampuan Koneksi Matematis Siswa Dengan Pendekatan Pembelajaran Metakognitif Di Sekolah Menengah Pertama. Jurnal Kultura 13 (1): 2832-2839

Kusnandar. 2011. Guru Profesional Edisi Revisi. Jakarta: Raja Grafindo Persada

NCTM. 2000. Principles and Standarts for School Mathematics. Reston. Virginia.

Nurfitria. 2013. Kemampuan Koneksi Matematis Siswa Ditinjau Dari Kemampuan Dasar Matematika di SMP. Jurnal Pendidikan dan Pembelajaran. Vol 2 (12)

Peterson, K. 2007. 55 Teaching Dilemas. Jakarta: PT Grasindo.

Sugiman. 2008. Koneksi Matematis dalam Pembelajaran Matematika di Sekolah Menengah Pertama. Phytagoras Vol 4 (1): 56-66

Sumarmo. 2013. Berfikir dan Disposisi Matematik Serta Pembelajarannya. FPMIPA UPI

Tomlinson. 2000. What is Differentiated Instruction? Alexandria: Association for Supervision and Curriculum Development.

Wahyudin. 2008. Pembelajaran dan Modelmodel Pembelajaran: Pelengkap untuk meningkatkan Kompetensi Pedagogis Para Guru dan Calon Guru Profesional. Bandung: Diktat Perkuliahan UPI 
